\title{
Diamide resistance: 10 years of lessons from lepidopteran pests
}

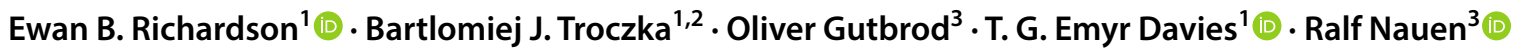

Received: 9 September 2019 / Revised: 21 February 2020 / Accepted: 28 February 2020 / Published online: 13 March 2020

(c) The Author(s) 2020

\begin{abstract}
Diamide insecticides selectively acting on insect ryanodine receptors (RyR) were launched to the market more than 10 years ago, particularly targeted for the control of lepidopteran pest species in diverse agronomic and horticultural cropping systems. They are now globally registered in many countries and provide reliable control levels in most settings. However, their frequent application, due to alternative mode of action chemistries often not providing sufficient levels of control, has resulted in the selection of diamide resistance in some of the world's most destructive lepidopteran species, including populations of diamondback moth, tomato leafminer, rice stem borer and more recently beet armyworm. High levels of diamide resistance, compromising diamide efficacy at recommended field rates, has been shown to be conferred by RyR target-site mutations affecting diamide binding. The present work reviews the global status of diamide insecticide resistance in lepidopteran pests, with special reference to RyR target-site alterations. Furthermore, we discuss principles enabling the prediction of the impact and spread of diamide resistance, based on population genetics and associated fitness costs as influenced by the known target-site mutations recently described. In this context, we reiterate calls by the Insecticide Resistance Action Committee to implement effective diamide insecticide resistance management by following a three-step strategy of resistance identification, tracking and prediction according to the protocols discussed in this article.
\end{abstract}

Keywords Insecticide resistance $\cdot$ Ryanodine receptor $\cdot$ Target-site resistance $\cdot$ Resistance management $\cdot$ Phylogeography Plutella xylostella $\cdot$ Tuta absoluta $\cdot$ Spodoptera frugiperda $\cdot$ Spodoptera exigua $\cdot$ Fall armyworm $\cdot$ Rice stem boorer

\section{Key message}

Communicated by N. Desneux.

Electronic supplementary material The online version of this article (https://doi.org/10.1007/s10340-020-01220-y) contains supplementary material, which is available to authorized users.

\footnotetext{
T. G. Emyr Davies

emyr.davies@rothamsted.ac.uk

Ralf Nauen

ralf.nauen@bayer.com

1 Department of Biointeractions and Crop Protection, Rothamsted Research, Harpenden, UK

2 Present Address: College of Life and Environmental Sciences, Biosciences, University of Exeter, Penryn Campus, Penryn, UK

3 Bayer AG, Crop Science Division, R\&D, 40789 Monheim, Germany
}

- Diamide insecticide resistance has reached levels compromising the control of some of the most destructive lepidopteran pest species at recommended field rates.

- The major mechanisms of resistance are reviewed, with particular reference to ryanodine receptor target-site mutations affecting diamide binding.

- A refined Lepidoptera ryanodine receptor homology model helps to further delimit the putative diamide binding site.

- Resistance management tactics based on identifying, tracking and predicting diamide resistance are considered key to conserve their efficacy. 


\section{Introductory statement}

Diamide insecticides display high target-mortality, fast action and a good toxicological profile (EbbinghausKintscher et al. 2007), all of which has contributed to their commercial success as an insecticide class (Sparks and Nauen 2015) (Fig. S1). Lepidopteran species, which are the primary diamide target, generally have wide ranging resistance to other insecticide classes, thus providing an immediate market demand for this novel chemistry when first launched over a decade ago. However, the popularity of this class of insecticide with a novel mode of action (MOA) has led to intensified selection pressure for the evolution of resistance (Troczka et al. 2017).

The Insecticide Resistance Action Committee (IRAC; a specialist technical group of the industry association CropLife) have developed guidelines to prolong insecticide efficacy through a three-pronged approach: Tracking of resistance episodes; Identification of resistance mechanisms and Prediction of future resistance events (Sparks and Nauen 2015). This overview addresses each approach individually in the context of management of diamide resistance, starting with a review of recent lepidopteran population expansion and novel resistance episodes. Despite reports of an imminent moth-mediated agricultural catastrophe (Stokstad 2017), advances in resistance tracking, lepidopteran migration monitoring and the development of novel diamide chemistry all give reasons to be optimistic.

\section{Tracking the global spread of diamide resistance}

A decade on from the first reports of diamide control failure in diamondback moth, Plutella xylostella (Troczka et al. 2012), resistance has evolved independently in at least nine lepidopteran species (Table 1 and in text). Subsequent expansion of some of these species out of their native range has been a major factor in the spread of diamide resistance, with several species making the transition from regional to global pest status. Global warming has increased invertebrate invasiveness, and globalisation has compounded the issue further (Chapman et al. 2017).

\section{Spodoptera frugiperda and other Noctuidae}

The fall armyworm, Spodoptera frugiperda, is a highly destructive pest of maize, frequently responsible for causing 40-70\% yield loss (Wyckhuys and O'Neil 2006). The caterpillars can additionally feed on at least 186 other plant species (Montezano et al. 2018), making this a broad-ranging and highly adaptable insect. Native to Central and South America, year-round populations extend southward to Brazil and Argentina, whilst migratory populations make their way annually from the Caribbean up the Eastern coast of the USA, as far north as Canada (Westbrook et al. 2016). However, the pest has recently spread outside of this range in a dramatic expansion that exemplifies the worrisome ease of movement of invasive species in the modern world (Fig. 1).

In Brazil, where insecticides are applied frequently to control lepidopteran pests, $S$. frugiperda is resistant to most synthetic chemistries. Diamide insecticides therefore have become an important element of integrated pest management (IPM) (Bolzan et al. 2019). Recently, however, resistance to chlorantraniliprole (CLR) was rapidly selected for in a field strain collected in Correntina, Bahia state, suggesting the presence of resistance alleles in the field (Boaventura et al. 2020). At the same time, $4000 \mathrm{~km}$ North, farmers in Puerto Rico were reporting reduced diamide control efficacy, with RRs of 160-fold against CLR and 500-fold against flubendiamide (FLB) being documented (Gutierrez-Moreno et al. 2019). Maize yields in these regions are comparably higher with respect to other South American nations (FAO 2019), which is most likely a reflection of the more intense insecticide application regimes in Brazil. Both S. frugiperda populations had previously developed Bt resistance, as reported in 2014, suggesting that the management practises and ecology of these populations are potentially conducive to resistance development (Boaventura et al. 2020). As of 2016, actual control failure likelihood remained low, with the LD80 still far below Recommended Dose (RD) for CLR (Table 1), suggesting that resistance spread could be delayed if the correct IRM strategies were implemented.

As diamide resistance was emerging over its native range; S. frugiperda populations were about to spread and have a major impact elsewhere. The moth was detected in Ghana and Togo (West Africa) in early 2016 (Nagoshi et al. 2017), heralding the start of an overseas invasion and expansion of unprecedented speed and scale, which would end with populations distributed across all the major maize producing regions of the globe. Barcoding analysis shows that the invaders are derived from the Florida gene pool, a migratory population whose range covers the USA, and extends south down to Puerto Rico (Nagoshi et al. 2017). Suspected to have been carried in the luggage-hold aboard a commercial aircraft, the moths quickly spread, sweeping across most of sub-Saharan Africa within just 16 months (Stokstad 2017). Sub-Saharan Africa was an ideal environment for moth expansion, with an average temperature well within its development range of $25-33{ }^{\circ} \mathrm{C}$ and medium to low rainfall for much of the year (Early et al. 2018). The moth's capacity to migrate thousands of kilometres on high-altitude winds allowed it to rapidly colonise the large tracts of open plains, which provided excellent rearing grounds (Westbrook et al. 


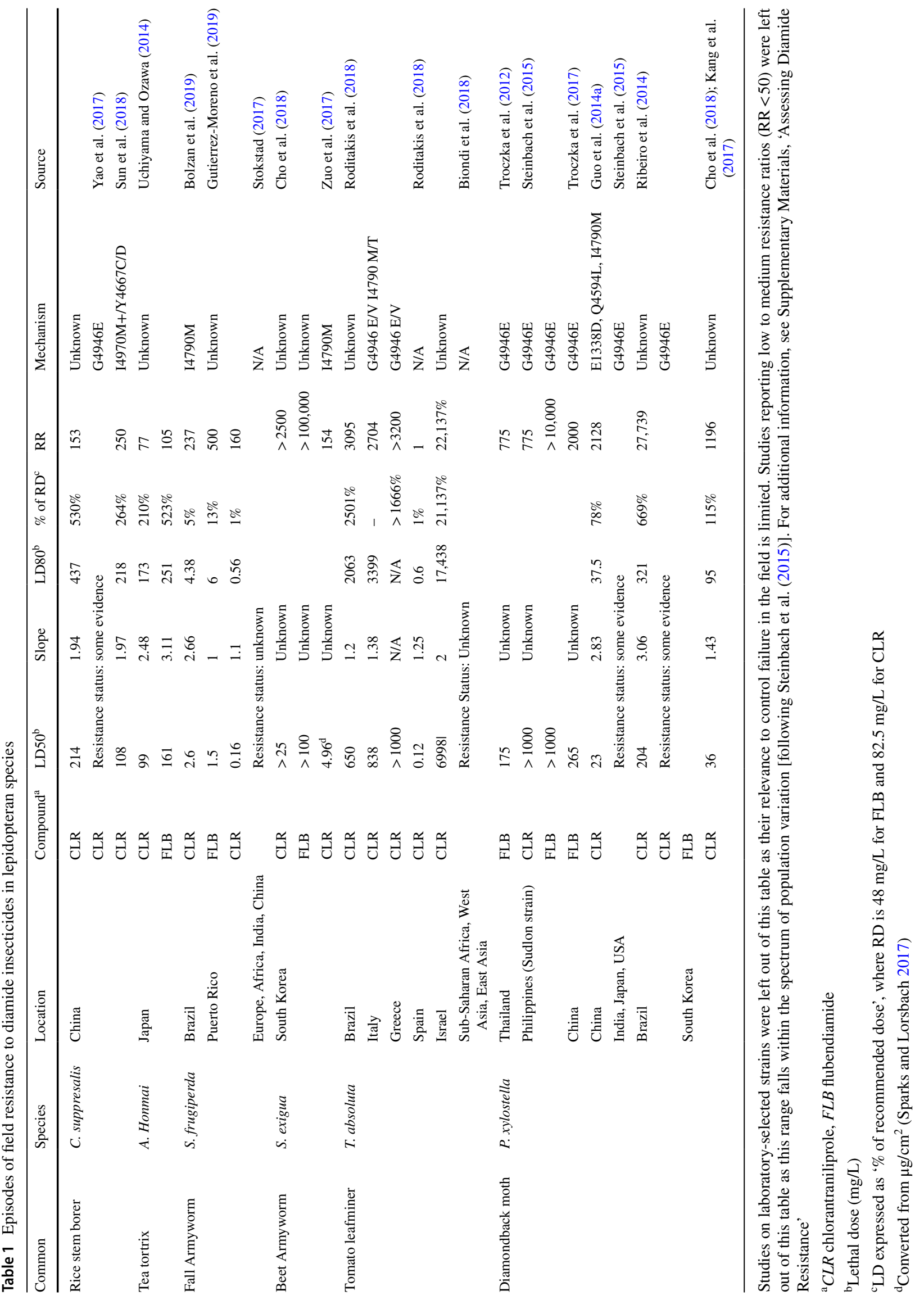




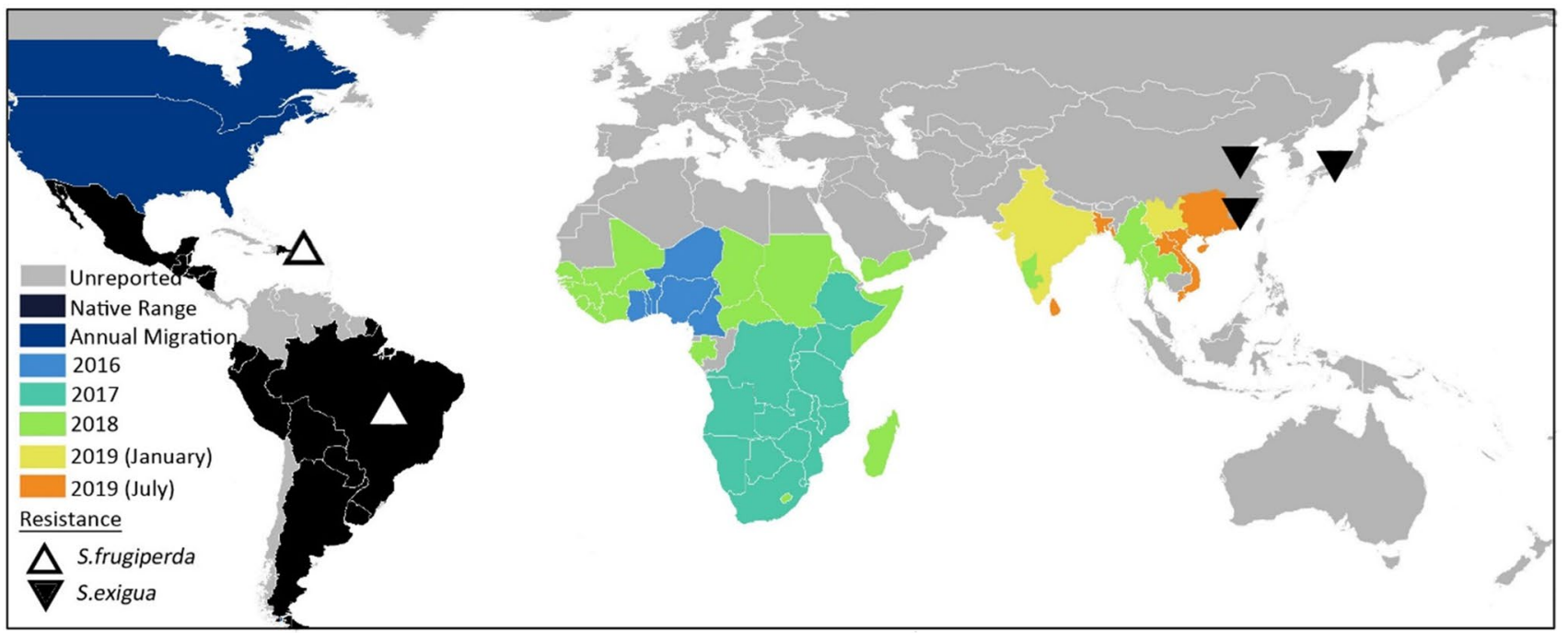

Fig. 1 Transnational spread of Spodoptera, with diamide resistance episodes of $S$. frugiperda and $S$. exigua labelled. Diamide resistance confirmed in Brazil and Costa Rica for S. frugiperda; in Shandong,

2016). After 2 years, it would inhabit 44 countries in Africa with permanent year-round populations (CABI 2019). The spread across Africa had been accurately predicted by a computational model, based on biotic, abiotic and human factors (Early et al. 2018). The same model warned that India would be the next target of invasion, and prescribed monitoring procedures to prevent a repetition of the airlineassisted route.

In May 2018, S. frugiperda was detected in Karnataka, India (Sharanabasappa et al. 2018). From there, it spread east into Myanmar and Thailand and, in January 2019, finally reached China. By April 2019 it had reached the southern edge of China's Corn-Belt, Hunan province (NATESC 2019), with predictions of a very rapid North-Easterly expansion (Li et al. 2020; Ma et al. 2019). As of July, the pest had already spread to 20 provinces, with high infestation levels in the sweet-corn producing southern regions (Ralf Nauen pers. comm.). It was also recorded, for the first time, in Kagoshima prefecture, Japan. Communications indicate that diamide, pyrethroid and emamectin benzoate sprays all currently remain effective in China and are being recommended in the emergency control guidelines issued by the Ministry of Agriculture and Rural Affairs (MARA). The National Agro-technical Extension and Service Centre (NATESC) has additionally established geographically specific control strategies including weekly forecasts and monitoring, biocontrol and potential chemical seed treatment.

Pinpointing the global spread's origin to the S. frugiperda Florida population raised the possibility that the African invaders may have been resistant to diamides (Nagoshi et al. 2017). Very few studies have reported on insecticide control efficacy since the spread. One study in Ethiopia
Jiangsu (China) and South Korea for S. exigua. Layout from Biondi et al. (2018); data from references in text and CABI invasive pest monitoring

reported close to baseline susceptibility towards diamides and several other insecticide classes (Sisay et al. 2019). If true, this is extremely fortunate, and is probably accounted for by an extreme genetic bottleneck in the founders of the Afro-Asian population, in which insufficient genetic diversity was present for resistance to emerge (Day et al. 2017). Cheaper sprays such as organophosphates and pyrethroids, rather than diamides, are the primary method of lepidopteran control across the continent, whilst parasitoids and predators compose the main IPM component within the widespread small-holder farming systems, all of which may help to slow the development of diamide resistance (Day et al. 2017). Two factors may increase the probability of resistance emergence now that the species has reached South-East Asia. First, diamide application in this area is traditionally high, whilst IPM practices have in the past been poor (Troczka et al. 2017). Second, this region harbours beet armyworm, Spodoptera exigua, and the track record of resistance development for this other noctuid pest may provide a worrying indication regarding future problems with S. frugiperda (Che et al. 2013).

The beet armyworm is a generalist pest, capable of targeting cereals, legumes (beans, peas), solanaceae (potatoes, tomatoes), cotton, tobacco and cannabis crops. Originating in East Asia, and reaching the Americas in the late nineteenth century, S. exigua is now a worldwide pest (Capinera 1999). As with other lepidopterans, this pest has evolved resistance to most approved products currently on the market (Che et al. 2013). It took just a few years for borderline control failures involving diamide insecticides to emerge in East Asia, with farmers in Jiangsu, China reporting a 44-fold resistance in 2010 (Lai et al. 2011; Che 
et al. 2013). By 2018, resistance had increased to 150 -fold and spread to Shandong (Zuo et al. 2019). Now, S. frugiperda is predicted to be heading towards the same area. Further east, in South Korea, extremely potent, 2500-fold diamide resistance has arisen in beet armyworm. In 2014, S. exigua resistance to diamides in South Korea had been noted as minimal; therefore, this case represents a prime example of the rate at which Lepidoptera, and noctuids in particular, are capable of adapting to diamide exposure (Cho et al. 2018). Finally, it is notable that Spodoptera litura has yet to develop meaningful diamide resistance. Reports from Southern China of diamide resistance in 2012 did not develop into a lasting crisis, with resistance in some regions returning to near-baseline by $2015 \mathrm{Cu}$ et al. 2012; Sang et al. 2016).

Helicoverpa armigera, the Old World bollworm, is a broad range pest that causes especially severe damage to tomato, soybean, corn and cotton crops (Cunningham and Zalucki 2014). A potent combination of physiological characteristics, including high fecundity (700 eggs/ female), migrational range (1000 km/generation), facultative diapause capability and drought tolerance, gives this pest high invasive capacity across a wide latitude [thoroughly reviewed in Tembrock et al. (2019)]. Ranging globally from Oceania, Asia, Europe and Africa, the Old World bollworm recently expanded its range dramatically by colonising the New World (CABI 2019). Detected in Bahia, Brazil, in 2013 (Tay et al. 2013), H. armigera is now present in Paraguay, Uruguay, Argentina, Bolivia and its presence is suspected in Peru, Surinam and the Dominican Republic (Gilligan et al. 2015). The risk of spread into North America is high, having already reached Puerto Rico, and multiple border incursions already detected in Florida (Kriticos et al. 2015). H. armigera is known to be resistant to a wide range of synthetic insecticides (McCaffery 1998). Furthermore, hybridisation with Helicoverpa zea, a North American heliothine pest, is expected to boost gene-pool size and thereby increase the adaptive capacity of both species to insecticide spray (Anderson et al. 2019). In response to this threat, multiple teams have established baseline susceptibility measurements against the anthranilamides, chlorantraniliprole (CLR) (Liu et al. 2017) and cyantraniliprole (CYA) (Bird 2016); however, bioassays are yet to report any indication of diamide resistance. The ryanodine receptor (RyR) gene has already been cloned for this species (Wang et al. 2013a) offering the potential for proactive resistance detection measures based on RyR sequencing (see section 'Target-Site Resistance'). Frequent monitoring of diamide susceptibility, especially in Brazilian populations, is recommended, both due to the history of lepidopteran diamide resistance development in this region, and due to the extensive tomato crop, which is a primary food source for $H$. armigera (Pratissoli et al. 2015).

\section{Tuta absoluta}

The tomato pinworm, Tuta absoluta, targets tomato crops through leaf mining and fruit infestation, although it can grow on other solanaceous species such as potato and nightshade. Yield losses on tomatoes have reached $100 \%$ where control has been inadequate (Desneux et al. 2010). In tomato plants, colonisation occurs early, meaning damage prevention requires a fast-acting means of control (Silva et al. 2011). However, as against other moth species, a heavy reliance on diamide insecticides has accelerated resistance development, especially as other MOAs had already lost efficacy and therefore were not available for rotation (Guedes et al. 2019; Silva et al. 2011). In a survey carried out in 2011, diamides provided excellent levels of control against Brazilian populations, with flubendiamide (FLB) LD50 at less than 0.1-0.25 mg/L (Campos et al. 2015). By 2014, high levels of resistance were present across the country, reaching $>100,000$-fold in Pesqueira and America Dourada (Silva et al. 2016).

As with other South American-derived pests, the optimal developmental temperature in T. absoluta is high; around $30{ }^{\circ} \mathrm{C}$ (Mohamadi et al. 2017). Capable of producing up to 10 generations per year in tropical climates and under greenhouse conditions, this pest was adapted to invade. Furthermore, unlike S. frugiperda, T. absoluta is capable of surviving short periods of near-freezing temperatures, potentially opening its range to a more northerly expansion (Biondi et al. 2018).

In 2006, T. absoluta was detected in Spain, having spread from a Chilean population (Biondi et al. 2018) (Fig. 2). Subsequent expansion down the coastal regions of Southern Europe was rapid. Collectively, Italy, Spain, Portugal and Greece produce some 15 megaTonnes $(\mathrm{mT})$ of tomatoes in 2017 (FAO 2019). Migration further northward was aided by greenhouse occupation. The Netherlands produces $0.9 \mathrm{mT}$ of tomatoes almost entirely under controlled environments, occupation of which seems to have allowed T. absoluta populations to expand year-round in otherwise less favoured northern latitudes (Van Damme et al. 2015). The rapid and immediate threat to European tomato production, and lack of alternative management strategies, prompted a heavy reliance on diamide applications (Desneux et al. 2010). The Chilean population that invaded Europe was already known to be resistant to pyrethroids and organophosphates (Silva et al. 2011). Unsurprisingly, diamide resistance development in Brazil was soon mirrored by resistance in Europe. As of 2013, highly resistant tomato leaf miner populations had been identified in greenhouses in southern Italy (Roditakis et al. 2015). A year later, CLR resistance was widespread 
across Italy, causing severe control failures in Sicily and the South (RR 1402-fold and 706-fold, respectively). T. absoluta in Greece remained susceptible until 2015, when a Cretan population quickly developed $>3200$-fold resistance (Roditakis et al. 2018). Other European nations are yet to report serious incidence of diamide resistance in this species. In North Yorkshire, UK, T. absoluta populations show EC50 values between 11 and $95 \mathrm{mg} / \mathrm{L}$ for CLR, indicating the possibility of imminent control failure (Grant et al. 2019). In Spain, resistance is notably lacking, despite populations having existed there since 2006 (Roditakis et al. 2018); however, there are indications that resistance could emerge (Zimmer 2018).

Other populations of T. absoluta had spread across Europe and on to Africa and Asia. In 2008, the coastal route had taken them to Morocco, and east to Turkey by 2009 . From there, it was predicted that they would spread to SubSaharan Africa and across the rest of Asia (Desneux et al. 2010). This forewarning did not prevent their onward expansion, however, and the pest reached South Africa (Sylla et al. 2017) and India (Han et al. 2018) in 2016. The resistance status of the African and East Asian populations is not clear, as they presumably disengaged from gene flow with the European population before the latter developed resistance. Very severe control failures registered in Israel in 2015, with 22,573-fold resistance against CLR, may be an independent episode distinct from that of the somewhat milder European resistance (Roditakis et al. 2018).

In the space of 10 years, a little known tomato-pest, which was present in just 3\% of global regions dedicated to tomato production, became a threat to $60 \%$ of worldwide tomato production (Biondi et al. 2018). Forecasts now look anxiously towards future invasions. Mexico produces $2 \mathrm{mT}$ of tomatoes per year, mostly under controlled environments, making it an ideal Tuta target (FAO 2019). However, tomato is not extensively grown in south-central America, which currently provides a $4000 \mathrm{~km}$ barrier between Mexico and California and moth populations in Columbia, Ecuador and Peru, meaning that any jump would have to happen via commercial transport or trade. The risk is that, if this does occur, invasion of the extensive Californian tomato vines will be almost immediate, as $95 \%$ of Mexican tomatoes are exported directly to the USA (FAO 2019). Lastly, $T$. absoluta is very likely to invade China. Producing almost a third of the world's tomatoes in 2017, and with subtropical climates in southern regions, China would be an excellent habitat for this pest (Han et al. 2018). India has already been invaded, and overland vegetable trade between India and China is extensive, suggesting that it is only a matter of time before T. absoluta arrives in China. However, the Chinese government has taken extensive measures to prevent such a circumstance, monitoring for the pest at 41,000 stations countrywide, in addition to the strategic deployment of more targeted surveillance strategies by the Chinese Department of Biological invasions (DBI) (Xian et al. 2017).

\section{Plutella xylostella}

The diamondback moth, Plutella xylostella, is a worldwide pest on cruciferous vegetables. Attempts to control the larvae, and to prevent their notoriously damaging tunnelling activity, equate to a gross annual expenditure of up to US \$ 2.3bn. Despite these measures, Plutella succeeds in causing US \$2.7bn of annual yield losses due to spoilage and crop damage (Zalucki et al. 2012). The pest bears a genome predisposed to xenobiotic adaptation (You et al. 2013) and an extensive capacity for adaptation by gene splicing (Troczka et al. 2018). With historical resistance to almost all synthetic insecticides, this is arguably one of the most resistant insect species on the planet (Whalon et al. 2016; Sparks and Nauen 2015). Assumed to have originated in the brassica homelands of Europe or Southern Africa, P. xylostella now makes its presence felt worldwide (Kfir 1998).

It was towards this species in particular that diamide insecticides were initially targeted. Breaking the insecticide resistance epidemic was an urgent necessity in China, where $46 \%$ of the world's brassica crops are produced (FAO 2019). An added bonus was the extremely high activity of FLB against $P$. xylostella (Ebbinghaus-Kintscher et al. 2007; Troczka et al. 2017). FLB was first launched in the Philippines in 2006 and subsequently in Thailand in May 2007. However, by December 2008 resistance would develop and control efficacy would be dramatically reduced in both countries (Fig. 3). Whilst early cases of resistance merely bordered on control failure (e.g. FLB 66.3-fold), resistance ratios quickly rose from 407-fold in Sai Noi, to 4817-fold in Tha Muang, to 26,602-fold in Pathum Thani (Troczka et al. 2017).

Episodes of resistance did not for long remain isolated to the Philippines and Thailand. In 2011, reports of resistance came from India and China (Troczka et al. 2017), followed by a rapid spread west across Asia. By 2013, resistance had reached Japan, but it also emerged, possibly independently, in Brazil and the USA (IRAC 2014). By 2014, it had spread to Vietnam, Indonesia and Korea (Steinbach et al. 2015; Kang et al. 2017; Cho et al. 2018).

\section{Diamide resistance in other lepidopteran species}

Resistance in Spodoptera, Tuta and Plutella species poses a phenomenal risk to associated crops in global agricultural systems. However, far from being exclusive to those species, damaging levels of diamide resistance have also been detected in Adoxophyes honmai (tea tortrix) and Chilo suppressalis (rice stem borer) and will be covered briefly below (Uchiyama and Ozawa 2014; IRAC 2014). Indications of 
low levels of resistance have also been reported for $\mathrm{Cna}$ phalocrocis medinalis (rice leafroller) (Zhang et al. 2014), Choristoneura rosaceana (oblique banded leaf roller) (Sial and Brunner 2012) and Chrysodeixis includens (soybean looper) (Owen et al. 2013), but will not be covered further here as they do not, as yet, compromise diamide field efficacy.

\section{Adoxophyes honmai}

Adoxophyes honmai, the tea tortrix, is a leaf mining pest of high-value crops such as tea, coffee, tobacco, citrus and cacao (CABI 2019). Whilst control via the parasitic wasp Macrocentrus homonae is highly effective in Sri Lanka and India, insecticide application is required outside of this range. Diamide efficacy on A. honmai was tracked over a period of 6 years following this insecticides introduction in Japan, with enlightening results (Uchiyama and Ozawa 2014). Applying FLB at the RD of 48 ppm gave $96 \%$ mortality in 2007, with mortality rates declining only gradually over the following year. Between 2009 and 2010 mortality dropped suddenly to just $52 \%$. Application of insecticide at sub-80\% mortality dosage (LD80) is associated with a dramatically increased probability of resistance emergence, which probably explains this pattern of gradual, followed by sudden, resistance (Silva et al. 2011). In this case, resistance severity continued to increase in the following years, reaching ratios of 105-fold (CLR) and 77-fold (FLB).

\section{Chilo suppressalis}

Chilo suppressalis is a devastating pest of rice that bores into the plant stem to cause 'dead heart', whereby the stem borer larvae kill the growing points of young shoots and surrounding leaves. Yield losses have been known to reach $100 \%$ (BAYER 2019) as the upper parts of the plant die off, leaves fall and the head becomes shredded. Believed to have originated in East Asia, C. suppressalis spread across the Pacific islands, down to Australia, and also west across the Silk Road and into southern Europe. It has thus colonised 84\% of the world's rice [by yield, (FAO 2019)], with West Africa and South America the only major rice producing regions left untouched. In an attempt to halt the damage, insecticides have been frequently applied, which has selected for resistance against organophosphates, fiproles and cartap (Yao et al. 2017). Diamides were first registered for control of $C$. suppressalis in China in 2008, with baseline susceptibilities of $0.1 \mathrm{mg} / \mathrm{l}$ (FLB) and $1.5 \mathrm{mg} / \mathrm{L}$ (CLR) (Wu et al. 2014; Gao et al. 2013). Resistance in C. suppressalis was first detected in Hubei in 2013 (IRAC 2014). Gradual declines in field efficacy followed in eastern China (spanning Hunan, Zheijiang and Shandong) in 2014, when RR's of 77.6 (CLR) and 42.6 (FLB) were recorded. Resistance values remained largely constant through 2015 (Lu et al. 2017), increasing to RR of 250 (CLR) by the end of 2016 in Jiangxi (Sun et al. 2018). Resistance in Chilo has remained moderate and constant over the past half-decade, with resistant moths remaining (at last check) at least partially susceptible (Sun et al. 2018). By comparison, most other episodes of resistance detailed in this section quickly escalated into complete control failure.

\section{Identifying the mechanisms of diamide resistance}

The extent of modern global pest monitoring means that new pest invasions can be tracked with sufficient accuracy to detect, in some cases, the first entry into a country, as with T. absoluta in Sicilian greenhouses (Roditakis et al. 2015). More helpful still were the accurate and precise predictions made of future spread for both T. absoluta (Desneux et al. 2010) and S. frugiperda (Early et al. 2018). One goal of IRAC is to see such population tracking successes mirrored in the context of insecticide resistance (Sparks and Nauen 2015). Efforts to track and predict resistance spread are augmented by identifying and characterising the cause of the resistance episode. Possible mechanisms include cuticular changes affecting insecticide penetration; behavioural adaptations for avoidance; metabolic upregulation to speed up detoxification and removal; and target-site alterations to reduce insecticide efficacy (IRAC 2019). Of these, metabolic resistance and target-site resistance (TSR) are the more common and serious threat to diamide efficacy and will be discussed further here.

\section{Metabolic resistance}

Phase I and phase II metabolism of xenobiotic compounds is thought to be mediated by three enzyme classes, cytochrome P450s (P450), carboxylesterases (CE) and glutathione S-transferases (GST) (Li et al. 2007). Metabolism of diamides in mammals has been shown to occur by oxidation, e.g. hydroxylation of alkyl groups (Yoshida 2014). Although diamide metabolism in insects is not well elucidated, several studies have found upregulation of P450, CE or GST genes as well as enzyme activity in response to insecticide exposure, suggesting that the mechanism is potentially similar. Recently, Li et al. (2017) found that overexpressed UDP-glycosyltransferases can also be involved in CLR resistance in P. xylostella. Modern synthetic insecticides frequently mimic plant defence compounds, and thus, it is no coincidence that exposure to plant allelochemicals such as alkaloids over an evolutionary timescale has given some insects a profound ability to react to novel toxic compounds; none more so than lepidopterans, and none more so than P. xylostella, whose genome has gene duplications in 
all three enzyme classes; P450s, CEs and GSTs (You et al. 2013).

Metabolic resistance has previously been implicated in potent episodes of resistance against other insecticide classes [e.g. (Zimmer et al. 2018)]. However, no such potent metabolic resistance has been documented for diamides to date. That being said, almost all investigations of TSR-mediated field resistance have found that metabolic pathways also participate. When TSR is isolated against a non-resistant background, resistance levels fall by a factor of ten or more (Douris et al. 2017; Zuo et al. 2019), suggesting that metabolic effects, although small in isolation, play an important combinatorial role with the more dramatic TSR component.

Metabolic resistance to diamide insecticides has been thoroughly reviewed in Nauen and Steinbach (2016). In general, studies have shown that upregulation of metabolic pathways does not equate to meaningful diamide resistance ratios, on its own. However, some notable cases of metabolic resistance exist, including that of a 43-fold CLR resistant Chinese strain of $C$. suppressalis, in which diamide susceptibility was restored almost entirely by $\mathrm{P} 450$ monooxygenase suppression (He et al. 2014). In Brazilian T. absoluta, P450 expression appeared to correlate with up to $\sim$ tenfold resistance ratios (Campos et al. 2015). In contrast, a study of eightfold resistant $C$. rosaceana found that esterase (not oxidase) suppression reversed the phenotype (Sial and Brunner 2012). Although none of these resistance cases translate to control failure in the context of recommended diamide dose rates, it is interesting to note the variation in metabolic pathways at play. Transcriptome and qRT-PCR studies have allowed a greater focus on the specific genes involved in diamide metabolism. An early transcriptome analysis confirmed the correlation between $\mathrm{P} 450$ gene expression levels and CLR resistance in P. xylostella (Lin et al. 2013). In subsequent studies, CYP6CV5, CYP9A68, CYP321F3 and CYP324A12 were found to be upregulated 40-fold in a $C$. suppressalis CLR-selected strain (Xu et al. 2019), whilst a P. xylostella CLR field-resistant population had an 80-fold upregulation of CYP6BGl (Li et al. 2018). In both cases, RNAi-mediated knockdown of the upregulated P450 genes led to minor increases in larval mortality to CLR at the RD. In S. exigua, transcriptome analysis of a CLR-selected strain found that CYP9A21v1,CYP9A21v2, CYP9A21v3 and $C Y P 9 A 21 v 4$ were upregulated and contributing to a resistance phenotype (Wang et al. 2018). It seems that various $\mathrm{P} 450$ s play a role in anthranilic diamide detoxification, although there is some variance across lepidopteran species, with one study of a laboratory-selected resistant $C$. suppressalis strain reporting UDP-glycosyltransferases as the mechanism of choice (Zhao et al. 2019), similar to another study showing the involvement of an overexpressed UDP-glycosyltransferase gene in P. xylostella (Li et al. 2017); however, in general the effects observed in these latest RNAi-assisted studies are relatively small in the context of TSR-mediated resistance.

Along with upregulation of metabolic enzymes, it has also been shown, exhaustively and repeatedly, that diamide resistance is associated with changes in RyR gene expression (Sun et al. 2012; Gong et al. 2014; Lin et al. 2013, 2015; Yan et al. 2014). Direction of change, up- or downregulation, is variable, although the size of the effect is generally so small $(0.5-2 \%)$ as to be biologically almost meaningless in the context of potent TSR- and metabolic-mediated control failures. Authors often claim that such changes are 'linked to diamide resistance' but inconsistent experimental design between studies and a failure to link transcript levels with actual protein abundance nullify such a conclusion. However, it is known from other studies that TSR causes functional changes to channels which can necessitate an adaptation in the number of channels expressed and/or the regulation of such channels (Bass 2017).

\section{Target-site resistance}

Diamides are conformation-sensitive activators of the insect RyR, a large (> $5000 \mathrm{kDa})$, tetrameric calcium channel present in the endo/sarcoplasmic reticulum of nerve and muscle cells. The binding sites (or 'Target-Sites') of FLB and CLR are thought to be distinct but allosterically coupled (Isaacs et al. 2012), probably located within the RyR transmembrane domain. Coinciding with the widespread use of diamide insecticides, amino acid polymorphisms on the RyR channel have emerged in lepidopteran pest species, associated with reduced diamide efficacy.

\section{The root of resistance-G4946 modifications in Plutella xylostella}

Just 18 months after their market introduction, resistance to diamide insecticides emerged in the Philippines in a population of diamondback moths and was quickly followed by further episodes in nearby locations (Troczka et al. 2012). Partial sequencing of the resistant $P$. xylostella populations soon revealed a commonality; a polymorphism, G4946E located close to the C-terminus of the RyR. An earlier study had shown the importance of this region in diamide efficacy, with C-terminal-ablated channels failing to bind the insecticide (Kato et al. 2009). The following five years would see numerous studies reporting the presence of the mutation in resistant diamondback moth populations from divergent locations (see references in Table 1). As the G4946E spread worldwide (Steinbach et al. 2015), its importance became clear, from functional evidence in insect cell lines, to binding studies on native membranes. Sf9 cells expressing a non-resistant wildtype (WT) $P x R y R$ channel exhibited non-transient gating and calcium store emptying in response 
to $100 \mathrm{nM}$ FLB application, whilst those expressing the G4946E channel were insensitive to such effects up to (and most likely beyond) the limit of solubility of the compound (Troczka et al. 2015). Similarly, native membrane preparations containing PxRyR from a resistant moth strain exhibited 450-fold (FLB) and 159-fold (CLR) reduced binding when compared to membrane preparations from a susceptible strain (Steinbach et al. 2015).

The G4946E mutation continues to emerge in new localities, with near-fixation of the mutation recently reported in South Korea (Kang et al. 2017). The differing coding triplets for the glutamic acid residue found in different populations (GAG for the Thai strain and GAA for the Sudlon (Philippines) strain) imply that this mode of resistance has evolved at least twice in Plutella (Troczka et al. 2012), whilst its incidence in at least 10 countries, spread across 3 continents, strongly suggests at least one more evolutionary event (Steinbach et al. 2015). An alternative substitution, G4946V, at this position has recently been characterised in P. xylostella populations from Guangzhou and Zhencheng in China, where the population make-up is split 70:30, G/E to G/V (Qin et al. 2018).

Additionally, mutation at this G4946 residue (P. xylostella numbering) has been implicated in resistance in other insect pest species. A glutamic acid rather than glycine is reported as being present in resistant $C$. suppressalis populations in China (Yao et al. 2017), whilst both G/E and G/V substitutions have been implicated in diamide resistance in European populations of T. absoluta (Roditakis et al. 2017). T. absoluta membranes harbouring G4946V-RyR have > 300-fold reduced FLB binding (Roditakis et al. 2017). Taken together, resistance-conferring changes at this position have emerged on a total of 8 separate occasions in the past decade, in each case rising from an allele-frequency of near zero and progressing to near-fixation. Whilst the RyR S4-S5 linker, as a whole, has been shown to be critical to channel gating (Ramachandran et al. 2013), non-conserved changes at the 4946 position, which have been selected for as a response to diamide exposure, appear to confirm that standing variation at this interface position between helix and linker can be maintained in the insect pest population. In support of this theory, fitness costs associated with the G/E mutation have been shown to be moderate, with some populations retaining the mutation without diamide selection (Troczka et al. 2017) (see below for a more detailed discussion). However, sequencing of weakly resistant lepidopteran populations frequently fails to detect G4946E, suggesting that residual mutant allele frequencies are below the $2-5 \%$ detection thresholds (Roditakis et al. 2017; Troczka et al. 2012; Guo et al. 2014a). Thus, for the resistant allele to rise to fixation from such depths requires that it provides a sufficiently large selective advantage. An overview of the past decade of scientific literature does indeed suggest that, in the presence of diamide selection, survivorship (i.e. RR) of G4946E/V mutants over wildtype is frequently increased $>3000$-fold (References in Table 1). Interestingly, when the G4946E mutation is inserted by CRISPR/Cas9 transgenesis into an otherwise susceptible genetic background, the resulting beet armyworm strain exhibits a somewhat modest resistance of (just) 223-fold to CLR (Zuo et al. 2017). This implies that, in reported cases of field resistance, resistance ratios recorded

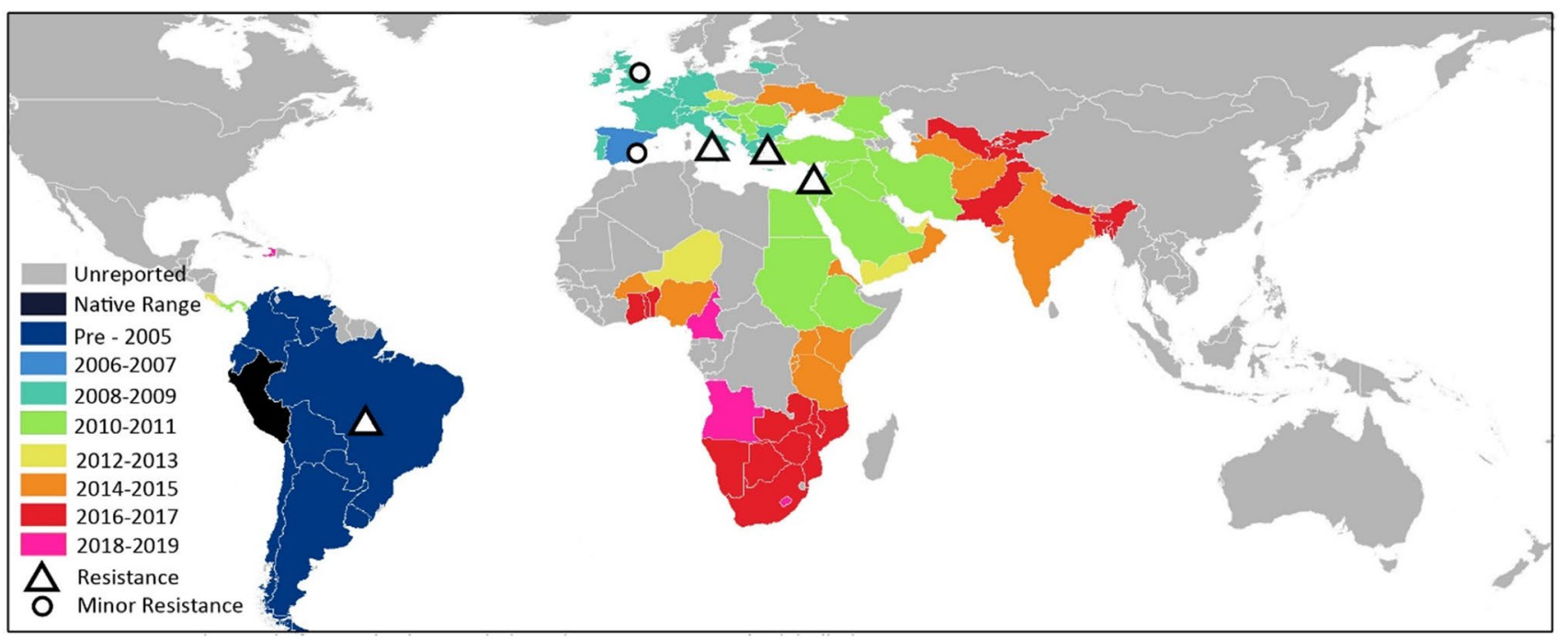

Fig. 2 Transnational spread of Tuta absoluta, with diamide resistance episodes labelled. Major diamide resistance episodes confirmed in Brazil, Italy, Greece and Israel. Minor or emerging resistance episodes are apparent in the UK (Grant et al. 2019) and Spain (Zimmer
2018). Layout from Biondi et al. (2018); distribution data from references in text and CABI invasive pest monitoring; Resistance data from Roditakis et al. (2018) and other references in text 
are the result of amplification of target-site resistance by the additional presence of metabolic resistance.

\section{0 - A novel cause of resistance in diverse lepidopteran pests}

Diamide resistance is no longer isolated to $P$. xylostella but is now also present in diverse populations of T. absoluta, $S$. frugiperda, S. exigua and C. suppressalis. Unsurprisingly, this diversification is coupled to the emergence of new genotypic mechanisms. One RyR amino acid residue in particular, I4790, is implicated in resistance within all of the species listed. Detected in resistant lepidopteran pests from Brazil, USA, Europe, Israel, China and Korea, this residue is developing a global importance to rival that of the G4946 locus.

The I4790 M change was first detected in a Chinese population of $P$. xylostella, one of a combination of four mutations identified in the RyR channel of this particular diamide-resistant strain, conferring potent ( $>2000$-fold) CLR resistance (Guo et al. 2014a). The potential significance of this residue is immediately clear when one looks at an alignment of insect RyRs (Table S3), as almost all insect orders are wildtype methionine (M), whilst Lepidoptera are distinguished from other orders by having an isoleucine (I). It seems highly plausible that the methionine at this position is therefore a selectivity switch, responsible for the relative ineffectiveness of diamides, particularly FLB, on non-lepidopteran pests (Steinbach et al. 2015). Such a theory is supported by reverse genetic studies in Drosophila, which naturally have methionine at this position and exhibit low diamide susceptibility. Substitution with isoleucine conferred a 7.5-fold increase in CLR efficacy and a 15-fold increase in FLB efficacy (Douris et al. 2017). In Diptera, anthranilic acid diamides such as CLR are thought to bind at a separate, albeit overlapping, location from the phthalic acid diamide FLB, potentially explaining this discrepancy in susceptibility in the engineered Drosophila strain (Qi and Casida 2013; Isaacs et al. 2012). A recent backcrossing experiment in $S$. exigua found that introgression of the I4790M mutation caused approximately 20 -fold resistance to both diamides (Zuo et al. 2019).

Functional biochemical studies on I4790M are severely lacking, and we still do not fully understand why this mutation causes diamide resistance. Homology protein modelling of the P. xylostella RyR has shown that this residue lies just $13 \AA$ from G4946 in the 3D structure (Steinbach et al. 2015), with suggestions that the two residues may form part of the diamide binding pocket. However, attempts to use a fluorescent CLR tracer to measure thoracic membrane binding failed to draw any meaningful conclusions (Guo et al. 2014b). A similar attempt using radiolabelled-CLR suggests 4790M-mediated reductions in binding, although presence of the G4946E residue in the membrane preparations prevents clear interpretation of the results (Roditakis et al. 2017).

Despite a lack of experimental validation, correlative evidence of I4790M conferring resistance is plentiful, as the mutation hitch-hikes its way across the globe. Its impact was first clearly shown in a Sicilian population of T. absoluta, in 2015, which exhibited 180-fold CLR resistance at a mutant-allelic frequency of close to $100 \%$ (Roditakis et al. 2017). It is now known to be fixed in various populations across Italy and Greece, where it appears

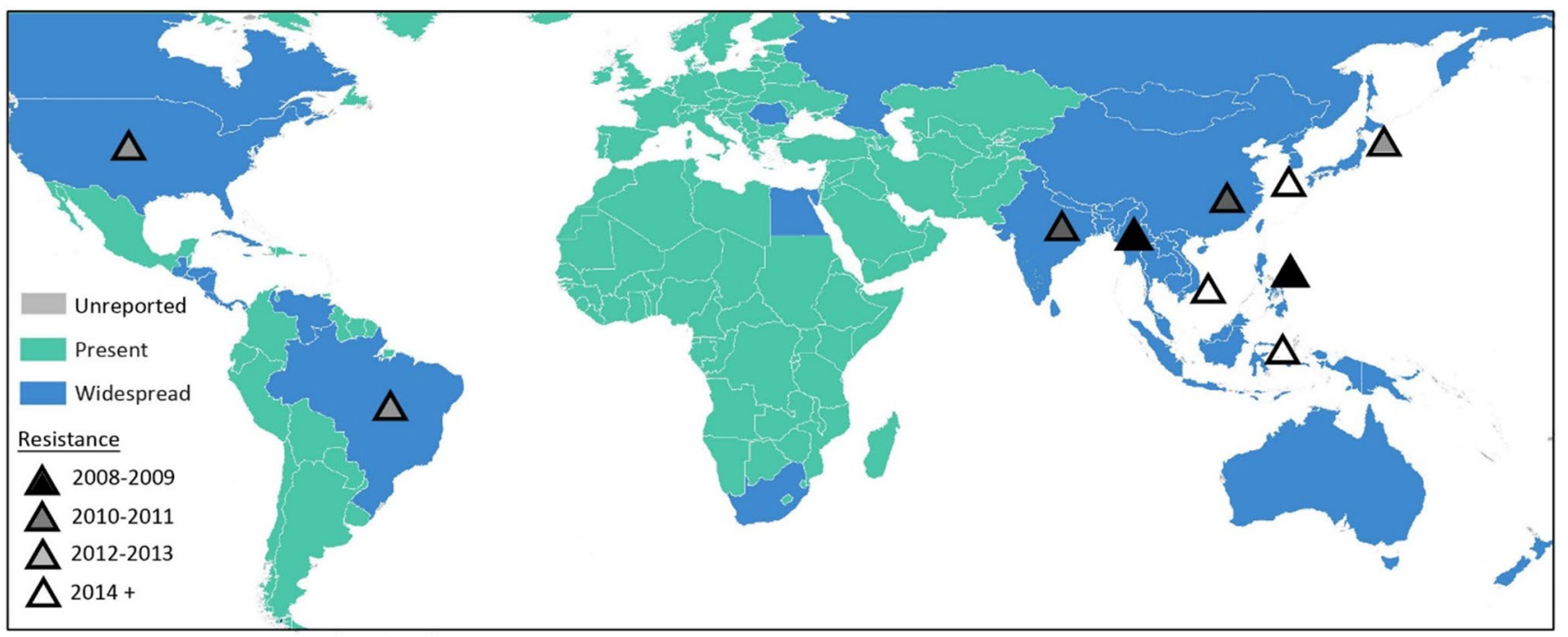

Fig. 3 Global distribution of Plutella xylostella with diamide resistance episodes labelled. Diamide resistance confirmed in Philippines, Thailand, India, China, Brazil, USA, Japan, Korea, Indonesia and
Vietnam. Layout from Biondi et al. (2018); distribution data from references in text and CABI invasive pest monitoring; resistance data from Steinbach et al. (2015) and other references in text 
to 'compete' with the G4946 mutations-the two changes almost never appearing in the same organism, with almost all local populations fixing for one or the other (Roditakis et al. 2017). I4790M has also been detected in South American populations of $S$. frugiperda (Boaventura et al. 2020). The Puerto Rican and Brazilian populations are described as distinct, although gene flow between the two is not unlikely (Nagoshi et al. 2017), but in any case both populations developed I4790M-mediated resistance in early 2016, with the Puerto Rican population exhibiting 160-fold (CLR) and 500-fold (FLB) resistance. Interestingly, laboratory selection of the Brazilian population with CLR led to a slight increase in CLR resistance (237-fold), but dramatic increases in FLB resistance ( $>42,000$-fold) (Bolzan et al. 2019). Another noctuid pest, S. exigua, also carries the equivalent of I4790M, which is present in almost all surveyed Chinese populations and is associated with 150-fold CLR resistance (Zuo et al. 2019). The mutation is also fixed in certain Chinese populations of C. suppressalis, associated with 250-fold CLR resistance (Sun et al. 2018). As all of these recorded cases closely associate with CLR resistance, I/M does certainly appear to be conferring resistance, although not to as high a degree as G4946E. However, as seen in Table 1, I/M resistance is certainly sufficient to cause control failure once it spreads to fixation.

A major missing piece of the resistance puzzle is how TSR and metabolic resistance combine to generate a potent resistance ratio, and so far, only one half of this picture has been resolved. In the context of TSR, isolation of G4946E in a wildtype lepidopteran background produces just 223-fold CLR resistance (Zuo et al. 2019); a tenfold reduction on the $>3000$-fold CLR field resistance in some Lepidoptera (Troczka et al. 2017), implying that other components are critical. On the other hand, studies that combine TSR observations with synergism experiments have shown some reduction in CLR resistance when P450s are blocked (Boaventura et al. 2020). A metabolic contribution of 20 - to 80 -fold in these studies contrasts sharply to the $<$ fivefold resistance effects registered in populations that lack TSR. The suggestion is that TSR and metabolic mechanisms combine factorially, rather than additively, explaining why each is drastically less severe in the absence of the other. Future work could involve a simple experiment, using gene editing to reverse a targetsite mutation in a resistant population. Bioassays on the resulting strain with and without $\mathrm{PBO}$, in the presence and absence of TSR, will reveal exactly the combinatorial nature of these two mechanisms. However, whilst further study on metabolic resistance is fundamentally interesting, it is unlikely to contribute significantly to the tracking and prediction of diamide resistance episodes, because the detoxification pathway appears to be composed of small, additive effects, and is highly variable between species. In practical terms, when what really matters is to limit the spread of resistance, further knowledge on target-site mutations potentially carries far greater importance if it can be used to develop effective global diagnostic/monitoring tools.

\section{New target-site alterations and mapping the diamide binding site}

Whilst this proliferation of target-site resistance is cause for alarm in terms of reduced pest defence, it may also hold clues to reversing resistance. Analysis of the resistanceassociated mutations described above, combined with empirical studies on the RyR channel, brings ever closer the goal of pinpointing the diamide binding site. Mapping of the P. xylostella TM region on to the available 3D structure of closed-state rabbit RyR1 (Yan et al. 2015) shows a very close proximity of G4946E and I4790M. At approximately $13 \AA$ distance, they face each other from either side of a Voltage Sensor Domain-like cavity (pVSD) (Fig. 4), a highly polar region whose homologues in other channels are known sites of ligand interaction. The role of the pVSD in diamide binding is supported further by a reverse genetic study on the D. melanogaster RyR, in which a 45-amino acid region was substituted for that of a nematode, Meloidogyne incognita, to form a chimeric channel, with the final five amino acids of this region (4697-4701, PxRyR numbering) causing particularly acute diamide insensitivity (Tao et al. 2013).

Intriguingly, the latest episodes of resistance in C. suppressalis add further support to the chimeric study. Unpublished reports from 2013 suggested a host of mutations associated with diamide resistance in China (Dan Cordova, pers. communication). All of these fell within the putative 'diamide resistance region' (Fig. 4, yellow dashes) previously identified (Steinbach et al. 2015), and they included G4946E, as well as various novel substitutions in close proximity. A recent publication confirms the presence of such novel substitutions, and in particular focuses on two novel substitutions at the Y4701 residue, 4701C and 4701D. Both changes, found in a resistant $C$. suppressalis population from Jiangxi, strongly correlate with diamide resistance (Sun et al. 2018). TSR reports in Chilo and other species were used here to further ascertain the probable diamideinteracting residues on the RyR channel. Each of these TSR associated positions was cross-compared against an alignment of 44 arthropod, nematode and vertebrate RyR amino acid sequences. Highly conserved residues, whose alteration correlates with diamide resistance, are considered good candidates for future binding site study (red dashes, Fig. 4). An overlay of all the hypothetical diamide-interacting residues upon a homology model of the PxRyR reveals that, in the 3D structure, these residues form a horizontal band 

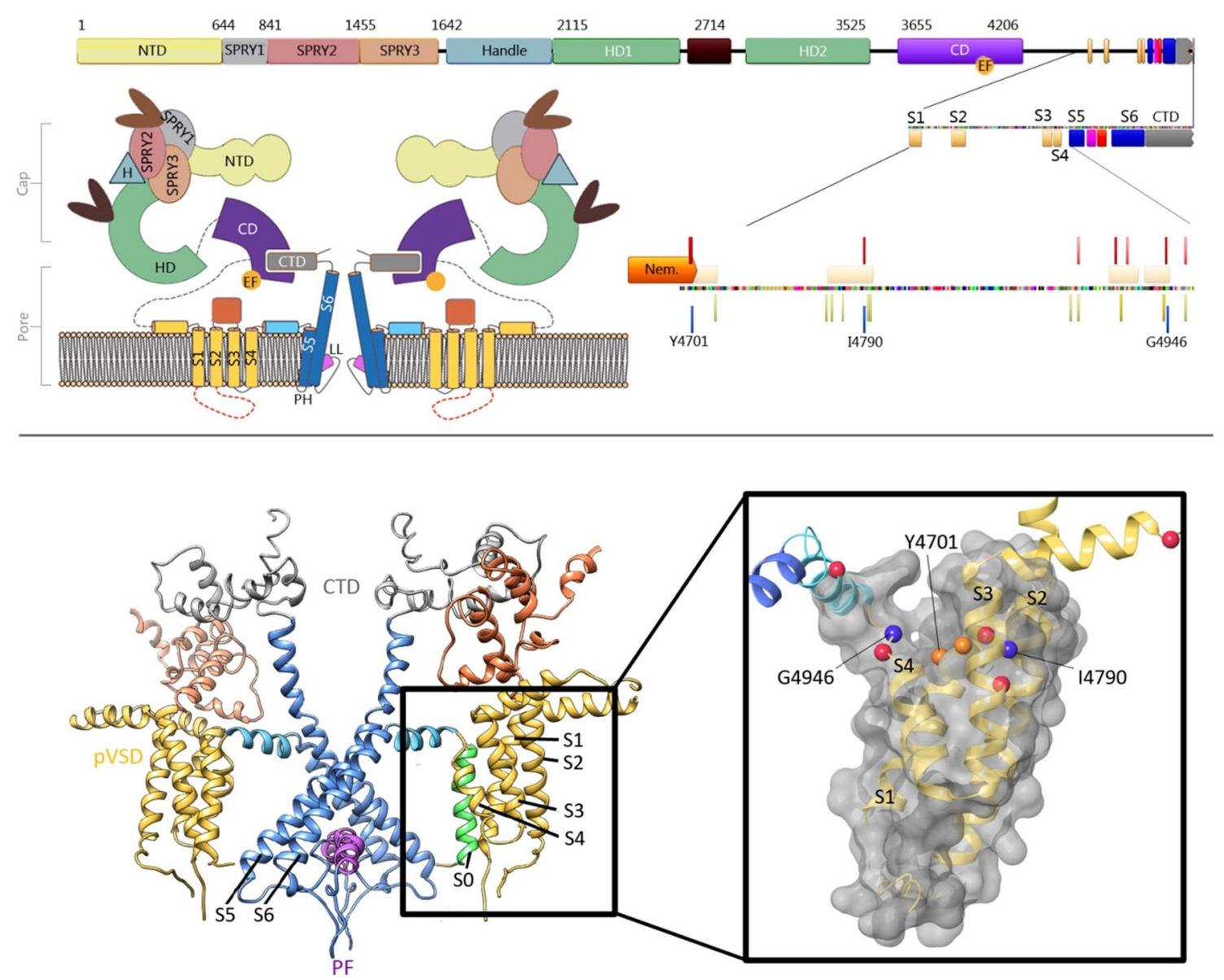

Fig. 4 Diamondback moth RyR 2D and 3D representations, with functional groups labelled as identified in the rabbit RyR1 sequence (Yan et al. 2015), with schematic representation of two opposing RyR sub-units from Zalk et al. (2015). Lower right-hand panel: magnification of S1-S4 reveals the 'diamide resistance region', with circumstantial evidence for diamide interaction. Top panel: Blue dashes indicate the principal 'field-resistance' mutations, Y4701C/D, I4790M/T, G4946E/V. Yellow dashes indicate additional SNPs found in Chilo suppressalis. Red dashes indicate highly conserved residues, whose alteration correlates with diamide inefficacy between animal phyla. 'Nem.' indicates the last five residues of the nematodecassette, responsible for diamide insensitivity when substituted into the D. melanogaster RyR channel, of which the final two residues, K4700 and Y4701, are labelled in the 3D structure (orange). Abbreviations: NTD (N-Terminal Domain); SPRY (SPla RyR); HD (Helical Domain); CD (Central Domain); EF (EF-hands); S1-6 (Solenoids); CTD (C-Terminal Domain); PH (Pore Helix); LL (Lumenal Loop); pVSD (Voltage Sensor-like Domain); PF (Pore Forming domain) close to the top of the pVSD. Although it is tempting to pinpoint the diamide binding site to this resistance-associated region, such conclusions may, however, be premature. Prediction of the diamide binding site in insects is currently based on a lepidopteran RyR structure which is constructed solely by reference to the published mammalian structure, due to the unavailability of high-resolution insect cryo-EM structures. Whilst recent imaging of the PxRyR N-terminus crystal structure represents an enormous leap forward (Lin et al. 2018), sequence dissimilarities at the C-terminus still preclude confident conclusions. Furthermore, binding is known to occur in the channel open-state $\left(\mathrm{Ca}^{2+}\right.$ activated) current open-state models of the pVSD (Des Georges et al. 2016) fall slightly short of the atomic resolution seen in the closed-state model (Zalk et al. 2015). Finally, as noted above, further functional investigations are required in order to establish which of these hypothetical resistance-associated residues are in fact responsible for altered diamide interaction.

\section{Predicting future resistance}

The data that now exist on lepidopteran TSR for diamide insecticides will enable highly precise and large-scale resistance tracking, if methods implemented recently (Boaventura et al. 2020) are adopted by the community at large. A powerful next step would be to predict the likely spread of TSRmediated resistance, in order to enact IRM protocols in advance of invasion. Population genetics can be employed 
to make such predictions, based on three pieces of information; the selective advantage, or Benefit, of a resistance allele, under insecticidal artificial selection; its selective disadvantage, or Cost, under both natural and insecticidal selection; and its Heritability [e.g. (Wilson and Rannala 2003)]. The first of the three, Benefit, is equivalent to the Resistance Ratios (RR) discussed above, where the RR indicates an increase in survivability under insecticidal application. The Heritability and Cost of diamide resistance will be the focus of this section, geared towards the ambitious goal of establishing a predictive model for diamide resistance spread.

\section{Heritability of diamide resistance alleles}

The heritability of a resistance phenotype is an indication of what proportion of that resistance is passed on to the following generation, when breeding occurs between resistant (RR) and susceptible (SS) strains. In most episodes of its occurrence, diamide resistance in Lepidoptera has been shown to be mediated primarily by TSR, and secondarily by metabolic resistance, as discussed above. TSR is expected to be a monogenic trait (assuming that the resistance mutations are clustered within a single gene), and inheritance is expected to be at least partially recessive because, by definition, the mutation mediates a reduction in protein activation. Studies on diamide resistance, over the past decade, have repeatedly confirmed these assumptions. For example, $>10,000$-fold FLB resistance in P. xylostella (mediated by G4946E) was found to be almost recessive (D-0.81) and near monogenic (Steinbach et al. 2015), and a gene editing study in S. exigua has proven that, when G4946E is the only mechanism, FLB resistance inheritance becomes completely recessive (D -1) (Zuo et al. 2017). A recent study confirms the same for CLR resistance in Tuta, where CEs, GSTs and P450s were shown not to contribute, and the resulting heritability was D -1 (Silva et al. 2018). By comparison, metabolic diamide resistance has been shown to be polygenic, with incompletely recessive inheritance (Wang et al. 2013b; Liu et al. 2015).

\section{Resistance has a cost}

The basal theory behind IRM MoA rotation is that of fitness costs: a phenotype is shaped by the selection pressures of its environment, bringing it ever closer to optimality in that environment, such that alterations to the environment, for example, by introduction of synthetic insecticides, predators or competitors, necessarily reduces the fitness of this phenotype (Coustau et al. 2000). On a genetic level, this is the reason that each resistance-causing allele can be described to suffer from a Cost in the absence of insecticidal pressure. The cause of the cost depends entirely on whether the resistance is metabolic (a quantitative trait) or TSR (a discrete trait). In the case of metabolic resistance, the cause of the trade-off is a straightforward trade-off between resource allocation into xenobiotic/toxin metabolism or allocation into nutrition metabolism. Transcriptome profiling of CLR-exposed C. suppressalis shows that, whilst detox genes are upregulated, the flipside is a downregulation of general metabolism genes (Meng et al. 2019), with metabolic reductions expected to cause reduction in development rate. Indeed, Culex pipiens mosquitoes which over-express esterases were shown to carry on average $30 \%$ less lipids, glycogen and glucose than their wildtype counterparts (Rivero et al. 2011).

\section{The cost of target-site resistance}

In the case of TSR, the cost is less predictable. Xenobiotics often take effect by altering the function of a constitutively expressed ('lethal') gene or protein, whilst TSR may counteract those effects by sequence modification of such genes. However, TSR sequence modifications are themselves associated with fitness effects, due to potential alterations to the function of the protein itself, and the biochemistry surrounding that. If functional effects of the mutation are significant, then the cost of resistance will be high. Plutella exhibiting 22,700-fold (TSR-mediated) CLR resistance produced fewer, smaller larvae, which took longer to develop and were less likely to successfully pupate, in the absence of CLR exposure, in comparison with the reference strain (Ribeiro et al. 2014). If, on the other hand, the mutation alters insecticide binding/activation properties without altering channel function, the cost of resistance can be close to zero. The Sudlon strain of Plutella, a laboratory reference strain taken from the Philippines during an early resistance outbreak, shows mild resistance-costs, in terms of 7-14\% delay in development across various larval and pupal stages (Steinbach et al. 2017); however, the strain continues to show high levels of resistance without further diamide selection (Steinbach et al. 2015), suggesting that such costs are not sufficient to reverse the resistance phenotype.

To our knowledge, no study has yet succeeded in modelling diamide resistance spread. However, as discussed herein, all necessary preconditions to such modelling have been met, with individual estimates of resistance cost, benefit and heritability having already been determined. One recent study, in diamide-resistant Tuta, studies heritability in the context of insecticidal exposure cost and benefit to show that the 'Effective Dominance' of the diamide resistance phenotype increases with decrease in insecticidal concentration (Silva et al. 2018). Such findings show empirically the importance of maintaining spray concentrations at sufficiently high dosage, but the findings also indicate the benefit that could be derived from a future empirically supported modelling effort. Such a study might involve two laboratory populations, each initially composed of $50 \%$ wildtype 
and 50\% TSR individuals, with one population receiving periodic diamide dosage. Frequent genotyping would allow detailed understanding of the cost and benefit of TSR over many generations, which would then inform a population genetic model of resistance dynamics which could be applied to potentially predict resistance spread in the field.

\section{General conclusion}

The problem of insecticide resistance is at least a century old (Guedes 2017), but a multitude of recent factors has exacerbated the rise of resistance to diamides in Lepidoptera. South-East Asian Plutella populations provide a worst-case scenario of how failed IRM can rapidly produce resistance, via lack of crop rotation, and overreliance on a single MoA (Troczka et al. 2017). A slowing down of new MoA discovery (Sparks and Lorsbach 2017), combined with increased regulatory pressure, further hampers insecticide MoA rotation, whilst globalisation increases the likelihood of novel pest invasions, and climate change expands their invasive range (Chapman et al. 2017). In this context, we reiterate calls for effective IRM [following (Guedes et al. 2019)], and we call for a three-step strategy of resistance Identification, Tracking and Prediction following the protocols mentioned in this article.

Acknowledgements Ewan Richardson received grant-aided support from Bayer CropScience through a Biotechnology and Biological Sciences Research Council funded Industrial studentship (BBSRC grant No BB/N504075/1). The work at Rothamsted forms part of the Smart Crop Protection (SCP) strategic programme (BBS/OS/CP/000001) funded through the Biotechnology and Biological Sciences Research Council's Industrial Strategy Challenge Fund.

Author contributions All authors participated in the designing of the manuscript, each focusing on their respective area(s) of expertise. The authors are responsible for the content.

\section{Compliance with ethical standards}

Conflict of interest The authors declare that they have no conflict of interest.

Ethical approval All applicable international, national and institutional guidelines for the care and use of animals were considered in the present study.

Informed consent The authors of this manuscript accept that the paper is submitted for publication in the Journal of Pest Science, and report that this paper has not been published or accepted for publication in another journal, nor is under consider at another journal.

Open Access This article is licensed under a Creative Commons Attribution 4.0 International License, which permits use, sharing, adaptation, distribution and reproduction in any medium or format, as long as you give appropriate credit to the original author(s) and the source, provide a link to the Creative Commons licence, and indicate if changes were made. The images or other third party material in this article are included in the article's Creative Commons licence, unless indicated otherwise in a credit line to the material. If material is not included in the article's Creative Commons licence and your intended use is not permitted by statutory regulation or exceeds the permitted use, you will need to obtain permission directly from the copyright holder. To view a copy of this licence, visit http://creativecommons.org/licenses/by/4.0/.

\section{References}

Anderson C, Oakeshott J, Taya W, Gordona K, Zwicka A, Walsh T (2019) Hybridization and gene flow in the mega-pest lineage of moth, Helicoverpa. Proc Natl Acad Sci USA 115:5034. https:// doi.org/10.1073/pnas.1718831115

Bass C (2017) Does resistance really carry a fitness cost? Curr Opin Insect Sci 21:39-46. https://doi.org/10.1016/j.cois.2017.04.011

BAYER (2019) Crop compendium. https://www.cropsciencebayercom/ en/crop-compendium/pests-diseases-weeds/pests/chilo-suppr essalis. Accessed 01 Sep 2019

Biondi A, Guedes RNC, Wan F-H, Desneux N (2018) Ecology, worldwide spread, and management of the invasive South American Tomato Pinworm, Tuta absoluta: past, present, and future. Annu Rev Entomol 63(1):239-258. https://doi.org/10.1146/annurevento-031616-034933

Bird LJ (2016) Susceptibility of Helicoverpa armigera (Lepidoptera: Noctuidae) to cyantraniliprole determined from topical and ingestion bioassays. J Econ Entomol 109(3):1350-1356. https ://doi.org/10.1093/jee/tow027

Boaventura D, Bolzan A, Padovez FEO, Okuma DM, Omoto C, Nauen R (2020) Detection of a ryanodine receptor target-site mutation in diamide insecticide resistant fall armyworm, Spodoptera frugiperda. Pest Manag Sci 76:47-54. https://doi.org/10.1002/ ps.5505

Bolzan A, Padovez FE, Nascimento AR, Kaiser IS, Lira EC, Amaral FS, Kanno RH, Malaquias JB, Omoto C (2019) Selection and characterization of the inheritance of resistance of Spodoptera frugiperda (Lepidoptera: Noctuidae) to chlorantraniliprole and cross-resistance to other diamide insecticides. Pest Manag Sci 75:2682-2689. https://doi.org/10.1002/ps.5376

CABI (2019) Invasive species compendium. https://www.cabiorg/isc/ search/index. Accessed 01 Sep 2019

Campos MR, Silva TBM, Silva WM, Silva JE, Siqueira HAA (2015) Susceptibility of Tuta absoluta (Lepidoptera: Gelechiidae) Brazilian populations to ryanodine receptor modulators. Pest Manag Sci 71(4):537-544. https://doi.org/10.1002/ps.3835

Capinera JL (1999) Beet armyworm, Spodoptera exigua (Hübner) (Insecta: Lepidoptera: Noctuidae). IFAS EENY105

Chapman D, Purse BV, Roy HE, Bullock JM (2017) Global trade networks determine the distribution of invasive non-native species. Glob Ecol Biogeogr 26(8):907-917. https://doi.org/10.1111/ geb. 12599

Che W, Shi T, Wu Y, Yang Y (2013) Insecticide resistance status of field populations of Spodoptera exigua (Lepidoptera: Noctuidae) from China. J Econ Entomol 106(4):1855-1862. https://doi. org/10.1603/ec13128

Cho S-R, Kyung Y, Shin S, Kang W-J, Jung DH, Lee S-J, Park G-H, Kim SI, Cho SW, Kim HK, Koo H-N, Kim GH (2018) Susceptibility of field populations of Plutella xylostella and Spodoptera exigua to four diamide insecticides. Korean J Appl Entomol 57(1):43-50

Coustau C, Chevillon C, Ffrench-Constant R (2000) Resistance to xenobiotics and parasites: Can we count the cost? Trends 
Ecol Evol 15(9):378-383. https://doi.org/10.1016/s0169 $-5347(00) 01929-7$

Cunningham JP, Zalucki MP (2014) Understanding Heliothine (Lepidoptera: Heliothinae) pests: What is a host plant? J Econ Entomol 107(3):881-896. https://doi.org/10.1603/ec14036

Day R, Abrahams P, Bateman M, Beale T, Clottey V, Cock M, Colmenarez Y, Corniani N, Early R, Godwin J, Gomez J, Moreno PG, Murphy ST, Oppong-Mensah B, Phiri N, Pratt C, Silvestri S, Witt A (2017) Fall armyworm: impacts and Implications for Africa. Outlooks Pest Manag 28(5):196-201. https://doi. org/10.1564/v28_oct_02

Des Georges A, Clarke OB, Zalk R, Yuan Q, Condon KJ, Grassucci RA, Hendrickson WA, Marks AR, Frank J (2016) Structural basis for gating and activation of RyR1. Cell 167(1):145-157. e117. https://doi.org/10.1016/j.cell.2016.08.075

Desneux N, Wajnberg E, Wyckhuys KAG, Burgio G, Arpaia S, Narváez-Vasquez CA, González-Cabrera J, Catalán Ruescas D, Tabone E, Frandon J, Pizzol J, Poncet C, Cabello T, Urbaneja A (2010) Biological invasion of European tomato crops by Tuta absoluta: ecology, geographic expansion and prospects for biological control. J Pest Sci 83(3):197-215. https://doi. org/10.1007/s10340-010-0321-6

Douris V, Papapostolou K-M, Ilias A, Roditakis E, Kounadi S, Riga M, Nauen R, Vontas J (2017) Investigation of the contribution of RyR target-site mutations in diamide resistance by CRISPR/ Cas9 genome modification in Drosophila. Insect Biochem Mol Biol 87:127-135. https://doi.org/10.1016/j.ibmb.2017.06.013

Early R, González-Moreno P, Murphy ST, Day R (2018) Forecasting the global extent of invasion of the cereal pest Spodoptera frugiperda, the fall armyworm. NeoBiota 40:25-50. https://doi. org/10.3897/neobiota.40.28165

Ebbinghaus-Kintscher U, Lummen P, Raming K, Masaki T, Yasokawa N (2007) Flubendiamide, the first insecticide with a novel mode of action on insect ryanodine receptors. Pflanzenschutz-Nachrichten Bayer 60(2):117-140

FAO_Food and Agricultural Organisation (2019) FAOSTAT. https:// www.fao.org/faostat/en (accessed 01.09.2019)

Gao C, Yao R, Zhang Z, Wu M, Zhang S, Su J (2013) Susceptibility baseline and chlorantraniliprole resistance monitoring in Chilo suppressalis (Lepidoptera: Pyralidae). J Econ Entomol 106(5):2190-2194. https://doi.org/10.1603/ec13058

Gilligan T, Goldstein P, Timm A, Farris R, Ledezma L, Cunningham A (2015) Identification of Heliothine (Lepidoptera: Noctuidae) larvae intercepted at U.S. ports of entry from the new world. J Econ Entomol 112:603. https://doi.org/10.1093/jee/toy402

Gong W, Yan HH, Gao L, Guo YY, Xue CB (2014) Chlorantraniliprole resistance in the diamondback moth (Lepidoptera: Plutellidae). J Econ Entomol 107(2):806-814

Grant C, Jacobson R, Ilias A, Berger M, Vasakis E, Bielza P, Zimmer CT, Williamson MS, Ffrench-Constant RH, Vontas J, Roditakis E, Bass C (2019) The evolution of multiple-insecticide resistance in UK populations of tomato leafminer, Tuta absoluta. Pest Manag Sci 75:2079-2085. https://doi.org/10.1002/ps.5381

Guedes RNC (2017) Insecticide resistance, control failure likelihood, $\&$ the first law of geography. Pest Manag Sci 73:479-484. https ://doi.org/10.1002/ps.4452

Guedes R, Roditakis E, Campos M, Haddi K, Bielza P, Siqueira H, Tsagkarakou A, Vontas J, Nauen R (2019) Insecticide resistance in the tomato pinworm Tuta absoluta: patterns, spread, mechanisms, management and outlook. J Pest Sci 92:1329-1342. https ://doi.org/10.1007/s10340-019-01086-9

Guo L, Liang P, Zhou X, Gao X (2014a) Novel mutations and mutation combinations of ryanodine receptor in a chlorantraniliprole resistant population of Plutella xylostella (L.). Sci Rep 4:6924. https://doi.org/10.1038/srep06924
Guo L, Wang Y, Zhou X, Li Z, Liu S, Pei L, Gao X (2014b) Functional analysis of a point mutation in the ryanodine receptor of Plutella xylostella (L.) associated with resistance to chlorantraniliprole. Pest Manag Sci 70(7):1083-1089. https://doi.org/10.1002/ ps. 3651

Gutierrez-Moreno R, Mota-Sanchez D, Blanco CA, Whalon ME, Teran-Santofimio H, Rodriguez-Maciel JC, DiFonzo C (2019) Field-evolved resistance of the Fall Armyworm (Lepidoptera: Noctuidae) to synthetic insecticides in Puerto Rico and Mexico. J Econ Entomol 112(2):792-802. https://doi.org/10.1093/jee/ toy372

Han P, Bayram Y, Shaltiel-Harpaz L, Sohrabi F, Saji A, Esenali UT, Jalilov A, Ali A, Shashank PR, Ismoilov K, Lu Z-Z, Wang S, Zhang G-F, Wan F-H, Biondi A, Desneux N (2018) Tuta absoluta continues to disperse in Asia: damage, ongoing management and future challenges. J Pest Sci 92:1317. https://doi.org/10.1007/ s10340-018-1062-1

He Y, Zhang J, Chen J (2014) Effect of synergists on susceptibility to chlorantraniliprole in field populations of Chilo suppressalis (Lepidoptera: Pyralidae). J Econ Entomol 107(2):791-796. https ://doi.org/10.1603/ec13414

Insecticide Resistance Action Committee (2014) eConnection. IRAC Newsletter (Issue 33)

Insecticide Resistance Action Committee (2019) IRAC Online. https ://www.irac-onlineorg/about/resistance/mechanisms/. Accessed 01 Sep 2019

Isaacs AK, Qi S, Sarpong R, Casida JE (2012) Insect ryanodine receptor: distinct but coupled insecticide binding sites for $\mathrm{N}-\mathrm{C}(3) \mathrm{H}(3)$ chlorantraniliprole, flubendiamide, and (3) $\mathrm{H}$ ryanodine. Chem Res Toxicol 25(8):1571-1573

Kang WJ, Koo HN, Jeong DH, Kim HK, Kim J, Kim GH (2017) Functional and genetic characteristics of chlorantraniliprole resistance in the diamondback moth, Plutella xylostella (Lepidoptera: Plutellidae). Entomol Res 47:394-403

Kato K, Kiyonaka S, Sawaguchi Y, Tohnishi M, Masaki T, Yasokawa N, Mizuno Y, Mori E, Inoue K, Hamachi I, Takeshima H, Mori $\mathrm{Y}$ (2009) Molecular characterization of flubendiamide sensitivity in the Lepidopterous ryanodine receptor $\mathrm{Ca}^{2+}$ release channel. Biochemistry 48(43):10342-10352. https://doi. org/10.1021/Bi900866s

Kfir R (1998) Origin of the Diamondback Moth (Lepidoptera: Plutellidae). Ann Entomol Soc USA 91(2):164-167. https://doi. org/10.1093/aesa/91.2.164

Kriticos DJ, Ota N, Hutchison WD, Beddow J, Walsh T, Tay WT, Borchert DM, Paula-Moreas SV, Czepak C, Zalucki MP (2015) The potential distribution of invading Helicoverpa armigera in North America: Is it just a matter of time? PLoS ONE 10(3):e0119618. https://doi.org/10.1371/journal.pone.0119618

Lai T, Li J, Su J (2011) Monitoring of beet armyworm Spodoptera exigua (Lepidoptera: Noctuidae) resistance to chlorantraniliprole in China. Pestic Biochem Physiol 101:198-205

Li X, Schuler MA, Berenbaum MR (2007) Molecular mechanisms of metabolic resistance to synthetic and natural xenobiotics. Annu Rev Ent 52(1):231-253. https://doi.org/10.1146/annur ev.ento.51.110104.151104

Li X, Zhu B, Gao X, Liang P (2017) Over-expression of UDP-glycosyltransferase gene is involved in chlorantraniliprole resistance in Plutella xylostella (L.). Pest Manag Sci 73(7):1402-1409

Li X, Li R, Zhu B, Gao X, Liang P (2018) Overexpression of cytochrome P450 CYP6BG1 may contribute to chlorantraniliprole resistance in Plutella xylostella (L.). Pest Manag Sci 74(6):1386-1393. https://doi.org/10.1002/ps.4816

Li X-J, Wu M-F, Ma J, Gao B-Y, Wu Q-L, Chen A-D, Liu J, Jiang Y-Y, Zhai B-P, Early R, Chapman JW, Hu G (2020) Prediction of migratory routes of the invasive fall armyworm in eastern 
China using a trajectory analytical approach. Pest Manag Sci 76:454-463. https://doi.org/10.1101/625632

Lin Q, Jin F, Hu Z, Chen H, Yin F, Li Z, Dong X, Zhang D, Ren S, Feng X (2013) Transcriptome analysis of chlorantraniliprole resistance development in the diamondback moth Plutella xylostella. PLoS ONE 8(8):e72314. https://doi.org/10.1371/ journal.pone.0072314

Lin L, Liu C, Qin J, Wang J, Dong S, Chen W, He W, Gao Q, You M, Yuchi Z (2018) Crystal structure of ryanodine receptor N-terminal domain from Plutella xylostella reveals two potential species-specific insecticide-targeting sites. Insect Biochem Mol Biol 92:73-83. https://doi.org/10.1016/j.ibmb.2017.11.009

Liu X, Wang HY, Ning YB, Qiao K, Wang KY (2015) Resistance selection and characterization of chlorantraniliprole resistance in Plutella xylostella (Lepidoptera: Plutellidae). J Econ Entomol 108(4):1978-1985. https://doi.org/10.1093/jee/tov098

Liu Y, Gao Y, Liang G, Lu Y (2017) Chlorantraniliprole as a candidate pesticide used in combination with the attracticides for lepidopteran moths. PLoS ONE 12(6):e0180255. https://doi. org/10.1371/journal.pone.0180255

Lu Y, Wang G, Zhong L, Zhang F, Bai Q, Zheng X, Lu Z (2017) Resistance monitoring of Chilo suppressalis (Walker) (Lepidoptera: Crambidae) to chlorantraniliprole in eight field populations from east and central China. Crop Prot 100:196-202. https://doi.org/10.1016/j.cropro.2017.07.006

Ma J, Wang Y-P, Wu M-F, Gao B-Y, Liu J, Lee G-S, Otuka A, Hu G (2019) High risk of the Fall Armyworm invading into Japan and the Korean Peninsula via overseas migration. BioRxiv. https://doi.org/10.1101/662387

McCaffery A (1998) Resistance to insecticides in Heliothine Lepidoptera: a global view. Philos Trans R Soc Lond B 353:1735-1750

Meng X, Dong F, Qian K, Miao L, Yang X, Ge H, Wu Z (2019) Transcriptome analysis reveals global gene expression changes of Chilo suppressalis in response to sublethal dose of chlorantraniliprole. Chemosphere 234:648-657. https://doi.org/10.1016/j. chemosphere.2019.06.129

Mohamadi P, Razmjou J, Naseri B, Hassanpour M (2017) Population growth parameters of Tuta absoluta (Lepidoptera: Gelechiidae) on tomato plant using organic substrate and biofertilizers. J Insect Sci 17:1-7. https://doi.org/10.1093/jisesa/iex011

Montezano D, Specht A, Sosa-Gómez D, Roque-Specht V, Sousa-Silva J, Paula-Moraes S, Peterson J, Hunt T (2018) Host plants of Spodoptera frugiperda (Lepidoptera: Noctuidae) in the Americas. Afr Entomol 26(2):286-300

Nagoshi RN, Koffi D, Agboka K, Tounou KA, Banerjee R, JuratFuentes JL, Meagher RL (2017) Comparative molecular analyses of invasive fall armyworm in Togo reveal strong similarities to populations from the eastern United States and the Greater Antilles. PLoS ONE 12(7):e0181982. https://doi.org/10.1371/ journal.pone.0181982

NATESC (2019) Recent reports of fall armyworm in China. Plant pathogen and pest information 2019-4-26

Nauen R, Steinbach D (2016) Resistance to Diamides in Lepidopteran Pests. In: Horowitz A, Ishaaya I (eds) Advances in insect control and resistance management. Springer, Dordrecht

Owen LN, Catchot AL, Musser FR, Gore J, Cook DC, Jackson R (2013) Susceptibility of Chrysodeixis includens (Lepidoptera: Noctuidae) to reduced-risk insecticides. Fla Entomol 96(2):554559. https://doi.org/10.1653/024.096.0221

Pratissoli D, Lima V, Pirovani V, Lima W (2015) Occurrence of Helicoverpa armigera (Lepidoptera: Noctuidae) on tomato in the Espírito Santo state. Hortic Bras 33:101. https://doi.org/10.1590/ S0102-053620150000100016

Qi S, Casida J (2013) Species differences in chlorantraniliprole and flubendiamide insecticide binding sites in the ryanodine receptor.
Pestic Biochem Physiol 107:321-326. https://doi.org/10.1016/j. pestbp.2013.09.004

Qin C, Wang C-H, Wang Y-Y, Sun S-Q, Wang H-H, Xue C-B (2018) Resistance to diamide insecticides in Plutella xylostella (Lepidoptera: Plutellidae): comparison between lab-selected strains and field-collected populations. J Econ Entomol 111(2):853-859. https://doi.org/10.1093/jee/toy043

Ramachandran S, Chakraborty A, Xu L, Mei YW, Samso M, Dokholyan NV, Meissner G (2013) Structural determinants of skeletal muscle ryanodine receptor gating. J Biol Chem 288(9):61546165. https://doi.org/10.1074/jbc.M112.433789

Ribeiro LMS, Wanderley-Teixeira V, Ferreira HN, Teixeira ÁAC, Siqueira HAA (2014) Fitness costs associated with field-evolved resistance to chlorantraniliprole in Plutella xylostella (Lepidoptera: Plutellidae). J Econ Entomol 104(01):88-96. https://doi. org/10.1017/s0007485313000576

Rivero A, Magaud A, Nicot A, Vézilier J (2011) Energetic cost of insecticide resistance in Culex pipiens mosquitoes. J Med Entomol 48(3):694-700. https://doi.org/10.1603/me10121

Roditakis E, Vasakis E, Grispou M, Stavrakaki M, Nauen R, Gravouil M, Bassi A (2015) First report of Tuta absoluta resistance to diamide insecticides. J Pest Sci 88(1):9-16. https://doi. org/10.1007/s10340-015-0643-5

Roditakis E, Steinbach D, Moritz G, Vasakis E, Stavrakaki M, Ilias A, García-Vidal L, Martínez-Aguirre MDR, Bielza P, Morou E, Silva JE, Silva WM, Siqueira HAA, Iqbal S, Troczka BJ, Williamson MS, Bass C, Tsagkarakou A, Vontas J, Nauen R (2017) Ryanodine receptor point mutations confer diamide insecticide resistance in tomato leafminer, Tuta absoluta (Lepidoptera: Gelechiidae). Insect Biochem Mol Biol 80:11-20. https://doi. org/10.1016/j.ibmb.2016.11.003

Roditakis E, Vasakis E, Garcia-Vidal L, Rosario Martinez-Aguirre M, Rison JL, Haxaire-Lutun MO, Nauen R, Tsagkarakou A, Bielza P (2018) A four-year survey on insecticide resistance and likelihood of chemical control failure for tomato leaf miner Tuta absoluta in the European/Asian region. J Pest Sci 91:421-431

Sang S, Shu B, Yi X, Liu J, Hu M, Zhong G (2016) Cross-resistance and baseline susceptibility of Spodoptera litura (Fabricius) (Lepidoptera: Noctuidae) to cyantraniliprole in the south of China. Pest Manag Sci 72(5):922-928. https://doi.org/10.1002/ps.4068

Sharanabasappa C et al (2018) First report of the Fall Armyworm, an alien invasive pest on maize in India. Pest Manag Hortic Ecosyst 24:23-29

Sial AA, Brunner JF (2012) Selection for resistance, reversion towards susceptibility and synergism of chlorantraniliprole and spinetoram in obliquebanded leafroller, Choristoneura rosaceana (Lepidoptera: Tortricidae). Pest Manag Sci 68(3):462-468. https://doi. org/10.1002/ps.2294

Silva GA, Picanço MC, Bacci L, Crespo ALB, Rosado JF, Guedes RNC (2011) Control failure likelihood and spatial dependence of insecticide resistance in the tomato pinworm, Tuta absoluta. Pest Manag Sci 67(8):913-920. https://doi.org/10.1002/ps.2131

Silva JE, Assis CP, Ribeiro LM, Siqueira HA (2016) Field-evolved resistance and cross-resistance of Brazilian Tuta absoluta (Lepidoptera: Gelechiidae) populations to diamide insecticides. J Econ Entomol 109:2190-2195. https://doi.org/10.1093/jee/tow161

Silva JE et al (2018) Field-evolved resistance to chlorantraniliprole in the tomato pinworm Tuta absoluta: inheritance, cross-resistance profile, and metabolism. J Pest Sci 92:1421-1431. https://doi. org/10.1007/s10340-018-1064-Z

Sisay B, Tefera T, Wakgari M, Ayalew G, Mendesil E (2019) The efficacy of selected synthetic insecticides and botanicals against fall armyworm, Spodoptera frugiperda, in Maize. Insects 10(2):E45. https://doi.org/10.3390/insects 10020045 
Sparks TC, Lorsbach BA (2017) Perspectives on the agrochemical industry and agrochemical discovery. Pest Manag Sci 73:672677. https://doi.org/10.1002/ps.4457

Sparks TC, Nauen R (2015) IRAC: mode of action classification and insecticide resistance management. Pestic Biochem Physiol 121:122-128. https://doi.org/10.1016/j.pestbp.2014.11.014

Steinbach D, Gutbrod O, Luemmen P, Matthiesen S, Schorn C, Nauen R (2015) Geographic spread, genetics and functional characteristics of ryanodine receptor based target-site resistance to diamide insecticides in diamondback moth, Plutella xylostella. Insect Biochem Mol Biol 63:14-22. https://doi.org/10.1016/j. ibmb.2015.05.001

Steinbach D, Nauen R, Moritz G (2017) Fitness costs of highly insecticide-resistant strains of Plutella xylostella at different temperatures. Pest Manag Sci 73:1789-1797. https://doi.org/10.1002/ ps. 4597

Stokstad E (2017) New crop pest takes Africa at lightning speed. Science 356(6337):473-474. https://doi.org/10.1126/scien ce. 356.6337 .473

Su JY, Lai TC, Li J (2012) Susceptibility of field populations of Spodoptera litura (Fabricius) (Lepidoptera: Noctuidae) in China to chlorantraniliprole and the activities of detoxification enzymes. Crop Prot 42:217-222. https://doi.org/10.1016/j.cropr o.2012.06.012

Sun LN, Cui L, Rui CH, Yan XJ, Yang DB, Yuan HZ (2012) Modulation of the expression of ryanodine receptor mRNA from Plutella xylostella as a result of diamide insecticide application. Gene 511(2):265-273. https://doi.org/10.1016/j.gene.2012.09.027

Sun Y, Xu L, Chen Q, Qin W, Huang S, Jiang Y, Qin H (2018) Chlorantraniliprole resistance and its biochemical and new molecular target mechanisms in laboratory and field strains of Chilo suppressalis (Walker). Pest Manag Sci 74(6):1416-1423. https:// doi.org/10.1002/ps.4824

Sylla S, Brévault T, Bal AB, Chailleux A, Diatte M, Desneux N, Diarra K (2017) Rapid spread of the tomato leafminer, Tuta absoluta (Lepidoptera: Gelechiidae), an invasive pest in Sub-Saharan Africa. Entomol Gen 36(3):269-283. https://doi.org/10.1127/ entomologia/2017/0453

Tao Y, Gutteridge S, Benner EA, Wu L, Rhoades DF, Sacher MD, Rivera MA, Desaeger J, Cordova D (2013) Identification of a critical region in the Drosophila ryanodine receptor that confers sensitivity to diamide insecticides. Insect Biochem Mol Biol 43(9):820-828. https://doi.org/10.1016/j.ibmb.2013.06.006

Tay WT, Soria MF, Walsh T, Thomazoni D, Silvie P, Behere GT, Anderson C, Downes S (2013) A brave new world for an old world pest: Helicoverpa armigera (Lepidoptera: Noctuidae) in Brazil. PLoS ONE 8(11):e80134. https://doi.org/10.1371/journ al.pone. 0080134

Tembrock LR, Timm AE, Zink FA, Gilligan TM (2019) Phylogeography of the recent expansion of Helicoverpa armigera (Lepidoptera: Noctuidae) in South America and the Caribbean Basin. Ann Entomoll Soc USA 112:388. https://doi.org/10.1093/aesa/saz019

Troczka B, Zimmer CT, Elias J, Schorn C, Bass C, Davies TGE, Field LM, Williamson MS, Slater R, Nauen R (2012) Resistance to diamide insecticides in diamondback moth, Plutella xylostella (Lepidoptera: Plutellidae) is associated with a mutation in the membrane-spanning domain of the ryanodine receptor. Insect Biochem Mol Biol 42(11):873-880. https://doi.org/10.1016/j. ibmb.2012.09.001

Troczka BJ, Williams AJ, Bass C, Williamson MS, Field LM, Davies TGE (2015) Molecular cloning, characterisation and mRNA expression of the ryanodine receptor from the peach-potato aphid, Myzus persicae. Gene 556(2):106-112. https://doi. org/10.1016/j.gene.2014.11.035

Troczka B, Williamson M, Field L, Davies E (2017) Rapid selection for resistance to diamide insecticides in Plutella xylostella via specific amino acid polymorphisms in the ryanodine receptor. Neurotoxicology 60:224-231

Troczka B, Richardson E, Homem R, Davies T (2018) An analysis of variability in genome organisation of intracellular calcium release channels across insect orders. Gene 670:70-86

Uchiyama T, Ozawa A (2014) Rapid development of resistance to diamide insecticides in the smaller tea tortrix, Adoxophyes honmai (Lepidoptera: Tortricidae), in the tea fields of Shizuoka Prefecture, Japan. Appl Entomol Zool 49(4):529-534. https://doi. org/10.1007/s13355-014-0283-x

Van Damme V, Berkvens N, Moerkens R, Berckmoes E, Wittemans L, De Vis R, Casteels H, Tirry L, De Clercq P (2015) Overwintering potential of the invasive leafminer Tuta absoluta (Meyrick) (Lepidoptera: Gelechiidae) as a pest in greenhouse tomato production in Western Europe. J Pest Sci 88(3):533-541. https://doi. org/10.1007/s10340-014-0636-9

Wang J, Liu Y, Gao J, Xie Z, Huang L, Wang W, Wang J (2013a) Molecular cloning and mRNA expression of a ryanodine receptor gene in the cotton bollworm, Helicoverpa armigera. Pestic Biochem Physiol 107:327-333. https://doi.org/10.1016/j.pestb p.2013.09.006

Wang X, Khakame SK, Ye C, Yang Y, Wu Y (2013b) Characterisation of field-evolved resistance to chlorantraniliprole in the diamondback moth, Plutella xylostella, from China. Pest Manag Sci 69(5):661-665. https://doi.org/10.1002/ps.3422

Wang X, Chen Y, Gong C, Yao X, Jiang C, Yang Q (2018) Molecular identification of four novel cytochrome $\mathrm{P} 450$ genes related to the development of resistance of Spodoptera exigua (Lepidoptera: Noctuidae) to chlorantraniliprole. Pest Manag Sci 74(8):1938-1952. https://doi.org/10.1002/ps.4898

Westbrook JK, Nagoshi RN, Meagher RL, Fleischer SJ, Jairam S (2016) Modeling seasonal migration of fall armyworm moths. Int J Biometeorol 60(2):255-267. https://doi.org/10.1007/ s00484-015-1022-x

Whalon M, Mota-Sanchez D, Hollingworth R (2016) Arthropod pesticide resistance database. https://www.pesticideresistanceorg/ indexphp. Accessed 01 Sep 2019

Wilson GA, Rannala B (2003) Bayesian inference of recent migration rates using Multilocus genotypes. Genetics 163:1177-1191

Wu M, Zhang S, Yao R, Wu S, Su J, Gao C (2014) Susceptibility of the rice stem borer, Chilo suppressalis (Lepidoptera: Crambidae), to Flubendiamide in China. J Econ Entomol 107(3):1250-1255. https://doi.org/10.1603/ec14053

Wyckhuys K, O’Neil R (2006) Population dynamics of Spodoptera frugiperda Smith (Lepidoptera: Noctuidae) and associated arthropod natural enemies in Honduran subsistence maize. Crop Prot 25:1180

Xian X, Han P, Wang S, Zhang G, Liu W, Desneux N, Wan F (2017) The potential invasion risk and preventive measures against the tomato leafminer Tuta absoluta in China. Entomol Gen 36(4):319-333. https://doi.org/10.1127/entomologi $\mathrm{a} / 2017 / 0504$

Xu L, Zhao J, Sun Y, Xu D, Xu G, Xu X, Zhang Y, Huang S, Han Z, $\mathrm{Gu} Z$ (2019) Constitutive overexpression of cytochrome P450 monooxygenase genes contributes to chlorantraniliprole resistance in Chilo suppressalis (Walker). Pest Manag Sci 75:718-725. https://doi.org/10.1002/ps.5171

Yan HH, Xue CB, Li GY, Zhao XL, Che XZ, Wang LL (2014) Flubendiamide resistance and Bi-PASA detection of ryanodine receptor G4946E mutation in the diamondback moth (Plutella xylostella L.). Pestic Biochem Physiol 115:73-77. https://doi.org/10.1016/j. pestbp.2014.09.003

Yan Z, Bai XC, Yan CY, Wu JP, Li ZQ, Xie T, Peng W, Yin CC, Li XM, Scheres SHW, Shi YG, Yan N (2015) Structure of the rabbit ryanodine receptor RyR1 at near-atomic resolution. Nature 517(7532):50-55. https://doi.org/10.1038/Nature14063 
Yao R, Zhao D, Zhang S, Zhou LQ, Wang X, Gao CF, Wu SF (2017) Monitoring and mechanisms of insecticide resistance in Chilo suppressalis (Lepidoptera: Crambidae), with special reference to diamides. Pest Manag Sci 73:1169-1178. https://doi. org/10.1002/ps.4439

Yoshida M (2014) Cyantraniliprole. In: Pesticide residues in food2013 part 2: toxicological evaluations. World Health Organization, Geneva. ISBN 9789241665292

You M, Yue Z, He W et al (2013) A heterozygous moth genome provides insights into herbivory and detoxification. Nat Gen 45:220 225. https://doi.org/10.1038/ng.2524

Zalk R, Clarke OB, desGeorges A, Grassucci RA, Reiken S, Mancia F, Hendrickson WA, Frank J, Marks AR (2015) Structure of a mammalian ryanodine receptor. Nature 517(7532):44-49. https ://doi.org/10.1038/nature13950

Zalucki MP, Shabbir A, Silva R, Adamson D, Liu SS, Furlong MJ (2012) Estimating the economic cost of one of the world's major insect pests, Plutella xylostella (Lepidoptera: Plutellidae): just how long is a piece of string? J Econ Entomol 105(4):11151129. https://doi.org/10.1603/Ec12107

Zhang S-K, Ren X-B, Wang Y-C, Su J (2014) Resistance in Cnaphalocrocis medinalis (Lepidoptera: Pyralidae) to new chemistry insecticides. J Econ Entomol 107(2):815-820. https://doi. org/10.1603/ec13506

Zhao J, Xu L, Sun Y, Song P, Han Z (2019) UDP-glycosyltransferase genes in the striped rice stem borer, Chilo suppressalis (Walker), and their contribution to chlorantraniliprole resistance. Int J Mol Sci 20(5):1064. https://doi.org/10.3390/ijms20051064
Zimmer CT (2018) Characterization and monitoring of target-site resistance in the ryanodine receptor of the tomato leafminer, $T$. absoluta In: XI European congress of entomology, Napoli 2-6 July 2018, pp 54-55

Zimmer CT, Garrood WT, Singh KS, Randall E, Lueke B, Gutbrod O, Matthiesen S, Kohler M, Nauen R, Davies TGE, Bass C (2018) Neofunctionalization of duplicated P450 genes drives the evolution of insecticide resistance in the brown planthopper. Curr Biol 28:268-274. https://doi.org/10.1016/j.cub.2017.11.060

Zuo YY, Wang H, Xu Y, Huang J, Wu S, Wu Y, Yang Y (2017) CRISPR/Cas9 mediated G4946E substitution in the ryanodine receptor of Spodoptera exigua confers high levels of resistance to diamide insecticides. Insect Biochem Mol Biol 89:79-85. https ://doi.org/10.1016/j.ibmb.2017.09.005

Zuo YY, Ma HH, Lu WJ, Wang XL, Wu SW, Nauen R, Wu YD, Yang YH (2019) Identification of the ryanodine receptor mutation I4743M and its contribution to diamide insecticide resistance in Spodoptera exigua (Lepidoptera: Noctuidae). Insect Sci. https:// doi.org/10.1111/1744-7917.12695

Publisher's Note Springer Nature remains neutral with regard to jurisdictional claims in published maps and institutional affiliations. 